\title{
От теории социальных сетей к моделированию сетевого взаимодействия (на примере российско-корейского делового партнерства на Дальнем Востоке России) ${ }^{1}$
}

\author{
Дарья Соколова*, Татьяна Селиванова \\ Дальневосточный федеральный университет, г. Владивосток, Россия
}

\author{
Информация о статье \\ Поступила в редакиџю: \\ 24.10.2019 \\ Принята к опубликованию: \\ 04.12.2019 \\ УДК 316.723 \\ JEL J01
}

Ключевые слова:

акторно-сетевая теория, акторно-сетевое взаимодействие, сетевое взаимодействие, российско-корейское сотрудничество

\section{Keywords:}

actor-network theory, actornetwork interaction, network interaction, Russian-Korean cooperation

\begin{abstract}
Аннотация
Основная идея исследования - это применение акторносетевой теории для анализа формирующегося сетевого взаимодействия российско-корейских предпринимателей. В статье описан первый этап теоретического и методологического обоснования исследования, определены подходы к моделированию реального акторно-сетевого взаимодействия. Дано обоснование необходимости и возможности использования различного аналитического инструментария для анализа отдельных составляющих исследовательских феноменов. Детально описана стратегия эмпирического исследования, направленная на обеспечение целостности и многозначности реальной анализируемой многофакторной среды деловой культуры с учетом эмоционального состояния респондентов.
\end{abstract}

From Network Theory to Network Interaction Modeling (the Example of the Russian-Korean Business Partnership in the Russian Far East)

Sokolova Daria, Selivanova Tatiana

\section{Abstract}

The main study idea is the Actor-network theory application to analyze the emerging network interaction between RussianKorean entrepreneurs. The paper describes the first stage of theoretical and methodological justification of the study; the approaches to modeling of real actor-network interaction are defined. Justification for the necessity and possibility of various analytical tools implementation for analysis of the certain studied phenomena's components is given. The empirical research strategy aimed at ensuring integrity and multi-importance of the

\footnotetext{
${ }^{1}$ Работа выполнена в рамках программы «Поддержка корееведения в ведущих зарубежных вузах» Министерства образования Республики Корея и Академии корейских исследований (Academy of Korean Studies) (AKS-2015-OLU-2250003)

*Автор для связи: sokolova.dand@dvfu.ru

DOI: https://dx.doi.org/10.24866/2311-2271/2019-4/152-161
} 
real analyzed business culture multi-factor environment considering the respondents' emotional state is described in detail.

As a result of the study, a sociocentric network model of Russian-Korean business interaction will be constructed as a set of separate models describing a set of different types of actions, control concepts in intersecting intercultural semantic fields.

The result of the study, aimed at understanding the process of formation and functioning of the network of Russian-Korean interaction, will make a strategic forecast for its development. And considering social networks as flexible social structures where individuals (collectives) are key elements, it is possible to manage network interaction through the communicative component, through the required behavior, which in general will contribute to the growth of a stable Russian-Korean partnership in the Russian Far East.

\section{Введение}

Теория социальных сетей соответствует такому состоянию социальных процессов и отношений, когда значение межличностных связей в экономике, политике и культуре начинает доминировать над системами и структурами, а взаимодействие социальных агентов преодолевает нормативные ограничения, свойственные любым социальным организациям, когда это взаимодействие приобретает «трансграничный» характер, идет поверх государственно или корпоративно установленных границ. Но именно в силу этой неформальности сетевого взаимодействия одной теории оказывается недостаточно для понимания конкретности социальных процессов. Каждый раз, в зависимости от особенностей социальных акторов, формируется уникальный комплекс сетевого взаимодействия. Вот почему для теории социальных сетей всегда востребован пул эмпирических исследований, которые, собственно, и позволяют увидеть, какого рода сети складываются в пространстве данного отношения. Мы полагаем, что исследование сетевого взаимодействия должно представлять собой программу, всегда открытую для учета его живой динамики. При формировании такой исследовательской программы важно заранее определить последовательность шагов и этапов. Покажем это на примере формирующегося сетевого российско-корейского делового партнерства [1].

Анализируя экономические институты как социальные конструкции (по Марку Грановеттеру), появляющиеся в их пределах устойчивые формальные и неформальные связи можно рассматривать как основу социальных сетей с их потенциалом личных связей, климата доверия и культуры общения, как социальный капитал, как ресурс дальнейшего наращивания взаимной выгоды от делового сотрудничества [2]. Но прямое наложение сетевой теории на конкретную ситуацию отношений окажется малопродуктивным. Проблема состоит не только в понимании структурно-функциональных особенностей конкретного сетевого взаимодействия, сколько в определении обоюдного влияния феноменов «социальная сеть делового сотрудничества» - «социальное поведение субъекта» в реальных социо-экономических условиях. Требуется предварительное построение социоцентрической сетевой модели этих отношений с учетом многих сопутствующих факторов, выявленных на основе проведение широких эмпирических исследований практик реального делового взаимоотношения. Учитывая то, что сотрудничество с Республикой Корея представляет для России исключительный интерес $[3,4,5]$ было бы полезно в качестве объекта исследования сетевого взаимодействия рассмотреть ряд российских и корейских компаний. Уже сегодня наши государства взаимодействуют в режиме наибольшего благоприятствования, показателем чего служит готовность ко- 
рейского государства и бизнеса инвестировать в развитие Дальнего Востока. В эпоху глобализации экономические институциональные системы России и Республики Корея мало чем отличаются, но этнографические и культурноисторические особенности функционирования этих систем на протяжении длительных исторических периодов сформировали особый вектор их развития. При общности экономических правил и норм взаимодействия, российскокорейские бизнес-партнеры не всегда понимают и верно интерпретируют субъективные модели поведения друг друга, институции в виде норм и обычаев, сложившиеся в процессе эволюции социокультурной деловой среды отдельных компаний [6]. Как правило, индивидуальный культурный опыт определяет особенности поведения, восприятия и оценки происходящего, что нельзя недооценивать при вхождении в инокультурную бизнес-среду.

Моделирование социальной сети российско-корейских бизнес отношений позволит осмыслить процесс их формирования, функционирования и сделать стратегический прогноз их развития.

\section{Теоретическое обоснование исследований}

Процесс формирования социальных сетей делового сотрудничества характеризуется многомерностью и многофакторностью, сложностью выделения объектной и предметной частей исследования [7]. Изучение таких сложных, открытых, саморазвивающихся эмерджентных систем с позиции человекоразмерности и культуроцентричности невозможно в рамках одной предметной области [8]. Поэтому исследование процесса формирования социальных сетей делового сотрудничества российско-корейских предпринимателей возможно только на основе междисциплинарного методологического подхода, используя широкий спектр инструментария различных научных подходов: постсоциентального, экономико-социологического, экономико-географического, экономико-институциального, социометрического, структурно-функционального, системного и др. подходов.

Проблеме междисциплинарных исследований, анализу противоречивости терминологии различных научных дисциплин, конфликтности теоретических основ самих подходов и их методологического несоответствия посвящен ряд аналитических работ $[8,9]$. Поэтому останавливаться на данной проблеме не будем и постараемся учесть в своих исследованиях основные теоретические положения. Полностью преодолеть все методологические противоречия между различными исследовательскими подходами нам не удастся, поэтому в дальнейшем важно грамотное обоснование применения тех или иных аналитических инструментариев для анализа различных составляющих исследуемого феномена.

При анализе процесса делового взаимодействия российско-корейских предпринимателей будем придерживаться теоретических основ методологического социологического индивидуализма, с позиции социо- и культуроцентричности, где рациональность «Ното есоnomicus» культурно и исторически обусловлена, где индивид рассматривается в «совокупности своих социальных связей и включенности в разнородные социальные структуры» [10].

В рамках экономико-географического подхода и его теорий новой экономической географии будут определены и описаны этапы экономической интеграции российско-корейских предпринимателей в формирующееся экономическое поле российского Дальнего Востока (по классификации Балашша Бела 
(Balassa Bela). Для оценки эффективности российско-корейской бизнесинтеграции будет использована модель эндогенного экономического роста.

Постсоциентальный и экономико-институциональный подходы, в которых в качестве «начальной точки исследования» рассматривается «человеческое взаимодействие», анализируется личность, ее «социальный опыт как источник понимания сложных социальных процессов», будем использовать для исследования неформальных механизмов бизнес-интеграции [11]. Целью применение институциональной теории В.Р. Скотта (Scott,1995, Kostova, 1997; Busenitz, Gomez, Spencer, 2000) является выделение в окружающей бизнессреде наряду с регулярными институтами, нормативной и когнитивной составляющими (Stenkolm, Acs, Wuebker, 2013; Orr, Scott, Rivera-Santos, Rufin, Kolk, 2012; Fink, Kibler, 2014). Нормативные институты, легитимность которых основана на морали, определяют социальную жизнь бизнес-сообщества, а именно, предпочитаемые индивидом социальные ценности и нормы, способы поведения [12]. Но понять и объяснить мотивы поведения, образ мыслей, ценностно-смысловые обоснования принятия тех или иных решений возможно только при анализе когнитивной составляющей институциональной бизнес-среды [12].

В исследовании будем опираться на полипарадигмальный подход экономической социологии, основанный на использовании основных концепций и аналитического инструментария социологии для анализа хозяйственных отношений (именно хозяйственных, а не экономических), включающих в себя как экономические, так и социальные аспекты хозяйственной деятельности [10]. Среди направлений новой экономической социологии наиболее применим к предмету нашего исследования сетевой подход, позволяющий осмыслить значимость различного рода социальных взаимодействий в едином социальном пространстве. Учитывая концептуальное разнообразие сетевой теории, применительно к проблематике исследования будет использована концепция «пространства потоков» Мануэла Кастельса и концепция «современной общности» и «социального капитала» Барри Уэллмана (Barry Wellman) $[13,14]$.

Сетевое взаимодействие российско-корейских предпринимателей будет проанализировано с использованием следующих моделей: 1) модель Карла Бруннера REMM - «человек изобретательный, оценивающий, максимизирующий полезность»; 2) модель социального человека Линденберга (Siegwart Lindenberg) SRSM - «человек социализированный, исполняющий роли поведение которого санкционировано обществом» [2].

Структурно-функциональный подход позволит рассмотреть сферу делового взаимодействия как сложную структуру, состоящую из множества взаимосвязанных элементов внутренней и внешней среды. В контексте концептуальной исследовательской модели будет использована модель бизнесэкосистемы, в которой социально-культурная среда является одной из определяющих состояния «здоровье бизнес-экосистемы» в целом.

Системный подход на основе теории Д. Истона и П. Шаран позволит выявить связи между предпринимателями, а также между интер- и экстросоциальными средами [15]. Анализ социальных явлений изучаемого экономического пространства будет выполнен на основе социометрического подхода, где социальные факторы являются приоритетными.

Опираясь на структуризацию социальных установок М. Смита (приводится по работам Е.П. Белинской, О.А. Тихомандрицкой, 2003), можем предположить, что доминирующими при формировании социальных сетей делового 
сотрудничества российско-корейских предпринимателей будут аффективная (эмоционально-оценочное отношение к объекту) и поведенческая (готовность индивида к осуществлению конкретного поведения по отношению к социальному объекту) социально-психологические установки [14]. Под социальнопсихологической установкой, опираясь на определение Гордона Олпорта (приводится по работам В.А. Соснина, Е.А. Красниковой), будем понимать психологическую готовность индивида вести себя определенным образом в социальной среде, с учетом собственного опыта и способностью регулировать социальное поведение в будущем [16].

Опираясь на институциональную теорию В.Р. Скотта и на структуризацию социальных установок М. Смита (по Е.П. Белинской, 2003) можем предположить, что доминирующими при формировании социальных сетей доверия между российскими и корейскими предпринимателями будут аффективная (эмоционально-оценочное отношение к объекту) и поведенческая (готовность индивида к осуществлению конкретного поведения по отношению к социальному объекту) стратегии [12].

\section{Методологическое обоснование исследований}

Говоря о сетевом взаимодействии, о формировании транснациональных сетей доверия возникает проблема их инструментального объектирования и исследования. В качестве предмета исследования в рамках российско-корейского делового сотрудничества будем рассматривать процесс становления и развития сетевых структур (социально-экономических акторов и устанавливающихся между ними связей и отношений), действующих в рамках единого экономического поля.

Выделение объекта исследования из-за многомерности и многофакторности рассматриваемого предмета, многообразия использования методологических подходов представляется достаточно сложным. В своих исследованиях, опираясь на теорию сетевого сообщества М. Кастельса, в качестве базового объекта исследования будем рассматривать сеть, составленную из разнообразного множества акторов (индивидуальных и коллективных), «постоянно модифицируемых по мере того, как сети приспособляются к поддерживающим их средам и рыночным структурам» $[13,14]$. Именно формирующаяся конфигурация системы действия акторов: связи - отношения (как устоявшиеся связи) - институты, и будет формироваться сетевое взаимодействие российско-корейских предпринимателей [17]. Объект исследования будет детализироваться для каждого исследовательского подхода в рамках установленного предмета исследования.

Анализируя формирующиеся социальные сети как ресурс устойчивого делового сотрудничества российско-корейского взаимодействия на российском Дальнем Востоке, на наш взгляд, необходимо решить следующие задачи:

1) определить структурные особенности устанавливающихся социальных связей и отношений между российскими и корейскими предпринимателями на основе анализа повседневных коммуникативных практик, формальных и неформальных правил и норм взаимодействия через сформированные субъектные модели поведения, через когнитивные схемы, модели связей на основе паттернов взаимодействия акторов, на основе многоуровневых исследований сетевых структур;

2) установить и описать процесс обоюдного влияния «социальная сеть»«социальное поведение субъекта» на примере взаимодействия российскокорейских предпринимателей; 
3) выполнить анализ процесса (вос)-производства социального капитала как интегративного результата сетевого взаимодействия, как ресурса развития российско-корейского предпринимательства на Дальнем Востоке;

4) выполнить структурно-функциональный анализ формирующегося сетевого пространства взаимодействия и его подсистем как совокупности позиции, ролей, прямых и опосредованных связей и отношений, потока ресурсов, накопления социального капитала.

В качестве анализируемого феномена будем рассматривать не экономических агентов - субъектов, принимающих участие в экономических отношениях на основе мотивов выгоды, а субъектов «действующих» (следуя теории Алена Турена). Учитывая многозначность теоретического конструкта - актор, в рамках исследования для нас представляет интерес не пассивный участник экономических отношений, а субъект, обладающий гибкой поведенческой логикой, способный выйти за пределы установленных норм и правил; полноправный участник бизнесотношений, генерирующий систему действий на основе собственного опыта и рефлексии [10]. Бизнес-отношения будем рассматривать как «повторяющиеся и предсказуемые связи между хозяйственными агентами» [10]. В рамках исследования интерес представляет субъективная позиция актора - его мотивы и концепции контроля. Под концепцией контроля (по В.В. Радаеву) будем понимать «совокупность смыслов, позволяющих интерпретировать происходящее и объяснять свои собственные поступки» [10].

Деловые взаимоотношения между акторами, экономические действия (по М. Веберу) анализируем как форму внутренне мотивированного социального действия [18]. Реализацию экономических действий акторов будем рассматривать через социальные структуры различного уровня: межличностное взаимодействие, институциональные структуры - нормы и правила, имеющие культурный контекст, организационные структуры.

Учитывая то, что исследования проводятся в соответствии с концепцией сетевого сообщества, где наибольший интерес для исследователя представляет сам человек в его реально существующем контексте, в качестве стратегии эмпирического исследования должен использоваться метод кейс-стади. Данная стратегия позволяет сохранить целостность и многозначность реальной анализируемой многогофакторной среды деловой культуры с учетом эмоционального состояния респондентов. Согласно классификации Р. Йгена, как один из исследовательских инструментов будет использовано множественное, индивидуальное описательное кейс-стади, которое позволит подробно описать процесс установления и развития сетевого взаимодействия российско-корейских предпринимателей на основе анализа отдельной личности, его социального опыта и ценностно-смысловых установок. В качестве источника информации для кейс-стади выбрано гайдинтервьюирование с четко заданной структурой и нестандартизованными ответами на вопросы.

Анализируемые феномены социокультурной бизнес-среды являются не явно выраженными, ненаблюдаемыми латентными переменными («hypothetical construct» по Грэму Харману, «не поддающимися прямому измерению» по J.C. Nunnally). Поэтому для их анализа необходимо использовать прокси-переменные, достаточно достоверно коррелируемые с изучаемыми латентными переменными. Для ограничения влияния неоднородности выборки может быть применен один из робастных методов, направленных на отслеживание выбросов в процессе траскрибирования интервью и их анализа при более пристальном внимании к отбракован- 
ным наблюдениям. С целью повышения устойчивости к некорректным данным, к факторам, не учтенным на этапе разработки программы интервью, в качестве прокси-переменных должно использоваться несколько индикаторов из разных блоков.

Сетевой анализ позволит описать структурные свойства сети российскокорейских предпринимателей и оценить степень их взаимодействия. Будем рассматривать сеть как гибкую (открытую, саморазвивающуюся, саморегулирующуюся) многоуровневую социальную структуру, состоящую из акторов: 1) работающих на Дальнем Востоке российских и корейских компаний (макроуровень); 2) владельцев, руководителей, менеджеров высшего звена (мидиуровень); 3) руководители подразделений анализируемых компаний (макроуровень) и множества связей и отношений в виде потока ресурсов (материальных и нематериальных). Математически социальную сеть будем рассматривать как графы различного уровня с множеством узлов-акторов и ребер (дуг) - поток ресурсов или как матрицы. Для построения социограмм и сетевых метрик будет определен перечень исследуемых атрибутов акторов и характеристики связей (интенсивность, длительность, наполненность, направленность и др.) [19].

\section{Заключение}

Опыт ранее выполненных исследований $[6,8]$ показывает, что наиболее достоверный и доступный исследовательский подход - это анализ «доминирующей социальной практики», а именно «целенаправленного взаимодействия и обмена между социальными акторами», возникающих на основе определенных социальных (профессиональных) отношений и сопровождающихся, как правило, «передачей различного рода ресурсов (материальных и нематериальных)» [14]. Анализ повседневных практик делового взаимодействия, определение сценариев экономического действия и их категоризация на основе вычленения отдельных типов позволят сформировать схемы рутинной активности (скрипты) взаимодействия партнерских российско-корейских компаний. Анализ стандартов поведения, построение когнитивных схем, позволит установить наиболее эффективные для российско-корейского делового сотрудничества концепции контроля, сформированные на основе рефлексивного опыта успешных деловых стратегий отдельных компаний.

При моделировании сетевого взаимодействия будут решены следующие задачи:

- изучены и описаны процессы «притяжения и отталкивания» между ведущими российско-корейскими бизнес-партнерами (по Джекобу Леви Морено);

- на основе концепции Фрица Хайдера будет оценен баланс и устойчивость анализируемой сетевой структуры на основе анализа «плотности сети» (по Watts, Strogtz, 1998) и концепции «слабых связей» Марка Грановеттера (по Gronovetter, 1982);

- на основе анализа повседневных коммуникативных практик, установленных доминирующих поведенческих паттернов, опираясь на различные модели коммуникации, будут установлены структурные свойства сетевого взаимодействия (выделены зоны первого, второго и т.д. порядка, уставлен тип их взаимодействия);

- будет дана оценка ценности, значимости акторов на основе их позиционирования в сети, определяемое удельным количеством реальных и потенциально возможных связей и отношений с акторами различных зон сети (а также за ее пре- 
делами), особенно in-degree связями - количеством обращающихся, зависимых от рассматриваемой сетевой позиции.

В результате будет построена социоцентрическая сетевая модель российскокорейского делового взаимодействия как совокупность отдельных моделей, описывающих совокупность различных типов действия, концепций контроля в пересекающихся интеркультурных смысловых полях $[2,10]$. Разработанные модели будут подтверждены эмпирическими данными и позволят установить: 1) какие факторы способствуют взаимному переходу экономико-ориентированной логики поведения к логике социально-ориентированного действия российско-корейских бизнес-партнеров в реальных условиях экономики Дальнего Востока; 2) как реализуется взаимное влияние собственных стратегий действий и типовых для данного экономического взаимодействия концепций контроля (в первую очередь когнитивных) [10].

Полученный результат исследования, направленный на понимание процесса формирования и функционирования сетевого российско-корейского взаимодействия, позволит сделать стратегический прогноз его развития. А рассматривая социальные сети как гибкие социальные структуры, где ключевыми элементами являются индивиды (коллективы), возможно управление сетевым взаимодействием через коммуникативную составляющую, через требуемое поведение, что в целом будет способствовать росту устойчивого российско-корейского партнерства на российском Дальнем Востоке.

\section{Список источников / References}

1. Латур Б. Пересборка социального: введение в акторно-сетевую теорию. Москва, изд. дом Высшей школы экономики, 2014. 384 с. [Latur B. Peresborka social'nogo: vvedenie v aktorno-setevuyu teoriyu [Reassembling Social: An Introduction to ActorNetwork Theory]. Moscow, HSE Publishing House, 2014. 384 p.]

2. Радаев В.В. Экономическая социология. Москва, изд. дом ГУ-ВШЭ, 2005. 286 с. [Radaev V.V. Ekonomicheskaya sociologiya [Economic sociology]. Moscow, HSE Publishing House, 2005. 286 p.

3. Муталенко В.А. Транснациональные корпорации как основной фактор глобализации в экономическом развитии Республики Корея. Сб. статей «Новые тенденции социокультурных изменений в Корейском и Российском обществах»: отв. ред. Р.К. Тангалычева, В.В. Козловский, Санкт-Петербург, Скифия-принт, 2015, сс. 283-289. [Mutalenko V.A. Transnacional`ny`e korporacii kak osnovnoj faktor globalizacii $v$ e konomicheskom razvitii Respubliki Koreya [Transnational corporations as the main factor of globalization in the economic development of the Republic of Korea]. Collection of articles "New Trends in Sociocultural Changes in Korean and Russian Societies": Res. ed. R.K. Tangalycheva, V.V. Kozlovsky, St. Petersburg, Scythia-print Publ., 2015, pp. 283-289.]

4. Стратегия социально-экономического развития Дальнего Востока и Байкальского региона на период до 2025 года: распоряжение Правительства РФ от 28.12.2009. № 2094. [Strategiya social`no-e`konomicheskogo razvitiya Dal`nego Vostoka i Bajkal`skogo regiona na period do 2025 goda: rasporyazhenie Pravitel’stva RF ot 28.12.2009. № 2094. [The strategy of socio-economic development of the Far East and the Baikal region for the period up to 2025: order of the Government of the Russian Federation of December 28, 2009. No. 2094.]

5. Федоренко И.С., Воробьева Н.А. Перспективы развития российско-корейских отношений в контексте введения антироссийских санкций. Сб. статей «Новые тенденции социокультурных изменений в Корейском и Российском обществах»: отв. ред. 
Р.К. Тангалычева, В.В. Козловский, Санкт-Петербург, Скифия-принт, 2015, сс. 272-283. [Fedorenko I.S., Vorob`eva N.A. Perspektivy` razvitiya rossijsko-korejskix otnoshenij v kontekste vvedeniya antirossijskix sankcij [Prospects for the development of Russian-Korean relations in the context of the introduction of anti-Russian sanctions]. Collection of articles "New Trends in Sociocultural Changes in Korean and Russian Societies": Res. ed. R.K. Tangalycheva, V.V. Kozlovsky, St. Petersburg, Scythia-print Publ., 2015, pp. 272-283.]

6. Новые тенденции социокультурных изменений в Корейском и Российском обществах. Сб. статей: отв. ред. Р.К. Тангалычева, В.В. Козловский, Санкт-Петербург, Скифия-принт, 2015. 420 c. [Novy`e tendencii sociokul'turny`x izmenenij v Korejskom i Rossijskom obshhestvax [New trends in sociocultural changes in Korean and Russian societies]. Collection of articles: resp. ed. R.K. Tangalycheva, V.V. Kozlovsky, St. Petersburg, Scythia-print Publ., 2015. 420 p.]

7. Князева Е.И. Сетевая теория в современной социологии. Социология, 2006, № 2, сс. 82-88. [Knyazeva E.I. Setevaya teoriya v sovremennoj sociologii [Network theory in modern sociology]. Sociologiya $=$ Sociology, 2006, no. 2, pp. 82-88.]

8. Рыжова Н.П. Экономическая интеграция приграничных регионов. ИЭИ ДВО РАН, 2013. 352 c. [Ry`zhova N.P. E`konomicheskaya integraciya prigranichny`x regionov [Economic integration of border regions]. IEI FEB RAS, 2013. 352 p.]

9. Билан Ю.В., Чабелкова И. Интердисциплинарный подход к исследованию миграционных процессов. СоЦис, 2015, №9, сc. 70-74. [Bilan Yu.V., Chabelkova I. Interdisciplinarny $\mathrm{j}$ podxod $\mathrm{k}$ issledovaniyu migracionny`x processov [Interdisciplinary approach to the study of migration processes]. SoCis, 2015, no. 9, pp. 70-74.]

10. Радаев В.В. Еще раз о предмете экономической социологии. Экономическая социология, 2002, №3, cc. 21-34. [Radaev V.V. Eshhe raz o predmete e`konomicheskoj sociologii [Once again about the subject of economic sociology]. E'konomicheskaya sociologiya $=$ Economic sociology, 2002, no. 3, pp. 21-34.]

11. Вальденфельс Б. Повседневность как плавильный тигель рациональности. Москва, Прогресс, 1991. 462 c. [Val'denfel`s B. Povsednevnost` kak plavil’ny`j tigel ${ }^{`}$ racional'nosti [Everydayness as a melting pot of rationality]. Moscow, Progress Publ., 1991. 462 p.]

12. Белинская Е.П., Тихомандрицкая О.А. Социальная психология. Москва, Аспект Преcc, 2003. 474 c. [Belinskaya E.P., Tixomandriczkaya O.A. Social naya psixologiya [Social Psychology]. Moscow, Aspect Press Publ., 2003. 462 p.]

13. Кастельс М. Информационная эпоха: экономика, общество культура. Москва, Аспект Пресc, 2000. 358c. [Kastel`s M. Informacionnaya e`poxa: e`konomika, obshhestvo kul'tura [Information Age: Economics, Society Culture]. Moscow, Aspect Press Publ., 2000. 358 p.]

14. Птицына С. Теория сетевого общества М. Кастельса. Социологический анализ. Мюнхен, LAP LAMBERT Academic Publishing. 2011. 60 c. [Pticyna S. Teoriya setevogo obshchestva M. Kastel'sa. Sociologicheskij analiz [Theory of the network society M. Castells. Sociological analysis]. Munich, LAP LAMBERT Academic Publishing. 2011. 60 p.]

15. Левин Г.Д. Философские категории в современном дискурсе. Москва, Логос, 2007. 224 c. [Levin G.D. Filosofskie kategorii v sovremennom diskurse [Philosophical categories in modern discourse]. Moscow, Logos Publ., 2007. 224 p.]

16. Соснин В.А., Красникова Е.А. Социальная психология. Москва, ФОРУМ: ИНФРАM, 2004. 336 c. [Sosnin V.A., Krasnikova E.A. Social’naya psixologiya [Social Psychology]. Moscow, FORUM: INFRA-M Publ., 2004. 336 p.]

17. Оффенштадт Н. Словарь историка. Москва, Российская политическая энциклопедия, 2011. 222 c. [Offenshtadt N. Slovar` istorika [Dictionary of the historian]. Moscow, Russian Political Encyclopedia Publ., 2011. 222 p.] 
18. Вебер М. Основные социологические понятия. Москва, Прогресс, 1990. 808 с. [Veber M. Osnovny`e sociologicheskie ponyatiya [Basic sociological concepts]. Moscow, Progress Publ., 1990. 808 p.]

19. Назарчук А.В. Мультикультурализм в сетевом взаимодействии. Мониторинг общественного мнения: экономические и социальные перемены, 2012, №1(107), сс. 108-112. [Nazarchuk A.V. Mul tikul turalizm v setevom vzaimodejstvii [Multiculturalism in Networking]. Monitoring obshhestvennogo mneniya: e`konomicheskie i social`ny`e peremeny` = Public Opinion Monitoring: Economic and Social Change, 2012, no. 1(107), pp. 108-112.]

\section{Сведения об авторах / About authors}

Соколова Дарья Андреевна, кандидат экономических наук, доцент, доцент кафедры менеджмента, Школа экономики и менеджмента, Дальневосточный федеральный университет. 690022 Россия, г. Владивосток, о-в Русский, кампус ДВФУ, корпус G. E-mail: sokolova.dand@dvfu.ru Daria A. Sokolova, Candidate of Economics Sciences, Associate Professor, Associate Professor of the Department of Management, School of Economics and Management, Far Eastern Federal University. Building G, FEFU campus, Russky Island, Vladivostok, Russia 690922.

E-mail: sokolova.dand@dvfu.ru

Селиванова Татьяна Валерьевна, кандидат технических наук, доцент, ученый секретарь Дальневосточного регионального учебно-методического центра высшего образования, Дальневосточный федеральный университет. 690091, г. Владивосток, ул. Суханова, д. 8.

E-mail: selivanova.tv@dvfu.ru

Tatyana V. Selivanova, Candidate of Technical Sciences, Associate Professor, Scientific Secretary of the Far Eastern Regional Training Center of Higher Education, Far Eastern Federal University. 8 Sukhanova St., Vladivostok, Russia 690090.E-mail: selivanova.tv@dvfu.ru 